\title{
Understanding the effects of partisan identity on climate change
}

Kimberly C. Doell (https://orcid.org/0000-0002-0043-9609)*1, Philip Pärnamets (https://orcid.org/0000-00018360-9097)*1,2 ${ }^{*}$ Elizabeth A Harris ${ }^{1}$, Leor M Hackel (https://orcid.org/0000-0002-7959-0642) ${ }^{3}$, \& Jay J. Van Bavel (iD:0000-0002-2520-0442) ${ }^{1,4}$

1: Department of Psychology, New York University

2: Department of Clinical Neuroscience, Karolinska Institutet

3: Department of Psychology, University of Southern California

4: Center for Neural Science, New York University

*These authors contributed equally and are ordered alphabetically

This is a pre-print under review.

Current work count: 2535

Declaration of interest: none

Acknowledgements: KCD was supported by the Swiss National Science Foundation (no. P400PS_190997), PP was supported by Swedish Research Council (no. 2016-06793; 202002584) and the John Templeton Foundation (\#61378), EH was supported by the Social Science and Humanities Research Council of Canada (752-2018-0213), and JVB was supported by the John Templeton Foundation (\#61378). The opinions expressed in this publication are those of the author(s) and do not necessarily reflect the views of the John Templeton Foundation. 


\begin{abstract}
(117/120 words)
Partisan and ideological identities are a consistent barrier to the adoption of climate change mitigation policies, especially in countries where fossil fuel reliance is the highest. We review how understanding collective cognition may help overcome such barriers by changing norms, promoting cooperation, downplaying partisan identities, or leveraging other identities to promote pro-climate change beliefs and behaviors. We also highlight several gaps in the literature and lay out a brief roadmap for future research. This review highlights the important role that social identity plays, both in terms of a barrier and a potential solution, in aid of promoting climate change mitigation. We also propose several key areas where research is lacking, and identify specific future directions.
\end{abstract}

Keywords: Social identity, climate change, partisanship, social neuroscience, social psychology 


\section{Introduction}

Efforts to reduce the negative impact of climate change are urgently needed, and yet the adoption of such measures is occurring at an alarmingly slow rate [1]. One potential barrier is political, as political polarization is strongly linked to beliefs about the origins of climate change $[2 * *]$. To better understand why beliefs about climate change are polarized, we review research from social psychology and cognitive neuroscience. Next, we identify ways in which this research on collective cognition may be harnessed to increase climate change belief and action. Finally, we propose several key areas where research is lacking, and identify specific future directions.

\section{Partisanship}

Partisan and ideological identities are strong predictors of the belief in the anthropogenic causes of climate change [2**,3], especially in English-speaking countries [3]. For example, US Republicans are six times more likely to dismiss the role that humans play in climate change than Democrats [4]. While there is a similar link between right-wing ideology and climate change skepticism in several countries, in many other countries, this link is either much smaller or does not exist (e.g. across Europe [5]; see also [3,6]).

This divergence may stem from the fact that extreme partisan polarization about climate change has only developed fairly recently. For instance, the partisan gap between Democrats and Republicans was relatively small when George W. Bush started running for President in 1998 but was massive by the time Barack Obama became President a decade later [7], and it is still growing [8]. There is a stronger relationship between conservatism and climate skepticism in countries with greater fossil fuel reliance (i.e., carbon dioxide emissions) where vested interest groups spread climate change misinformation [9]. This is particularly problematic because it would mean that in some of the countries that contribute the most to climate change, there is the greatest division and gridlock when it comes to developing mitigation strategies.

Motivated partisan cognition is one psychological process through which identification with one's political group can influence beliefs about climate change. Information is processed differently by individuals depending on whether the source is an in- or out-group/party member $\left[10^{*}, 11\right]$. Thus, if your political party supports a policy or the out-group opposes it, you are more likely to also endorse it, independent from the content of the policy [12]. This phenomenon is amplified when information is endorsed/opposed by trusted political elites [13]. In fact, before the media and political elites depicted climate change as a partisan issue, it was met with relatively bipartisan support [14]. Further, making partisan identities salient can increase these biases. For example, right-wing Australians exhibited a reduction in climate change belief and pro-climate policy support after being primed with their political identity [15].

Partisan identity exerts a powerful influence on climate change beliefs, but it only represents one pathway by which social identity processes influence beliefs and behaviors. Below, we outline how these processes may be changed, leveraged, or sidestepped entirely to promote climate change beliefs and behaviors.

\section{Changing identity norms}

Sharing a group identity encourages the enactment of group norms (i.e., the shared understanding about what conduct is both common and appropriate in a group [16]). People are very sensitive to normative information, and therefore behavior change interventions that specifically target descriptive norms (i.e., information about which behaviors are typical) have 
relatively large impacts on promoting or dissuading behaviors, including a variety of proenvironmental behaviors (see $[4,5,16]$ ).

The impact of norms on behavior is driven by our social identities: if other people in my group are changing their behavior, it suggests change is for "people like me". Therefore, establishing pro-climate norms in specific groups may increase the pro-climate beliefs and behaviors of individuals. Targeting groups that are skeptical of climate change could be particularly impactful. For example, drawing attention to evidence that a large portion of US Republicans actually do believe in climate change (e.g., [17]), or that the vast majority of Republicans support the expansion of solar panel and wind turbine farms [18], may help establish pro-climate norms amongst Republicans. Sending group-tailored messages to relevant audiences is likely the optimal way to spread such targeted normative information (see [2**]).

When norms are based on the perception of false information, they stand to problematically alter beliefs and behavior. For example, people substantially exaggerate how much partisans reactively devalue ideas coming from the opposition [17*]. Such false norms may lead to self-reinforcing polarization; "if I believe we/they are swayed by information coming from us/them, then I should also be similarly swayed". Further, this false norm about polarization may actually lead partisans to refrain from publicly supporting policies that they privately believe in, for fear of contradicting their in-group (see [17*]). Correcting this misperception of partisanship may go a long way to reduce polarization.

When it comes to establishing new norms, or correcting misperceived norms, political leaders have a large role to play. Although cues from political elites in the past helped make climate change a highly polarized topic $[2 * *, 14,19]$, it may be possible to reverse this damage by incentivising collective action and beliefs via identity leadership [20,21]. Trust likely plays an important role. If a cue comes from a trusted elite, it can significantly increase climate policy support (for both Democrats and Republicans), but if information comes from an untrusted source, it can backfire and reduce support [13].

Norm based interventions can also backfire, or simply have no impact on behavior. This effect has been shown across multiple types of norms, including injunctive norms (which highlight what is approved of), and descriptive norms (i.e. both positive, and negative [2**,13, 22]). For example, the use of a positive social norm conveying citizen's increased proenvironmental behavior had no effect on influencing climate policy support, while a negative social norm conveying increased destructive-environmental behavior decreased policy support [13]. However, one promising technique may be to utilize dynamic norms, which highlight how people are beginning to change their behavior. For example, adding "people have changed their behavior" to a static-counter-normative message, i.e. "30\% of Americans [...] limit their meat consumption", greatly reduced meat eating intentions and behaviors across a variety of contexts [23]. These dynamic norms led people to believe that change is compatible with their social identities [24]. Harnessing such dynamics may represent an effective way to promote other proclimate behaviors or policy support.

\section{Social identity shapes cooperation}

Social identity can also lead people to value their in-group's welfare. From individuals deciding to buy more expensive, but environmentally-friendly products, to societies managing complex social-ecological systems like carbon emissions, many environmental behaviors are types of social dilemmas where people must incur a personal cost to benefit the larger group 
[25]. The more people identify with a group, the more willing they are to incur costs to benefit the group [26]. This appears to stem from increasing the subjective value individuals assign to their group's welfare. For example, even people who are low in prosociality give more to a group/group members when their shared identity is made salient [27].

Social neuroscience offers further evidence that social identity shapes social value. For instance, people show stronger responses in the ventral striatum--a region linked to subjective reward--when giving money to in-group versus out-group members [28,29]. The extent to which people identify with a social group correlates with their vicarious reward responses in the ventral striatum when observing in-group versus out-group members winning money [30]. Similarly, cooperation has been linked to brain regions more generally involved in subjective value of outcomes such as ventromedial prefrontal cortex and ventral striatum [31].

Shared identity can motivate contributions to an in-group while also demotivating contributions that help an out-group. This dynamic can shape large-scale cooperation for which people may volunteer when they think it helps their ingroup but not an outgroup [32]. At the same time, social identity is flexible; people experience different social identities as salient at different times, such as seeing themselves as a political partisan, an American, or a human [33]. Tapping into more inclusive, superordinate identities - such as identification with humanity-may therefore be necessary to promote cooperation towards climate change [34-36].

\section{Counteracting motivated partisan cognition}

One way to reduce motivated partisan cognition is to increase accuracy goals $\left[10^{*}, 37 * *\right]$. For instance, asking Americans to justify their positions, which amplifies the goal to be accurate, increases the likelihood that they update their beliefs, support green technology and legislation, and ultimately reduces partisan bias [38]. Similarly, prompting partisans to carefully consider graphs, which shows global temperature trends, reduces identity motivated cognition [39]. For Republicans, the evidence was most effective when the graphs were coupled with statements from a neutral scientific authority (i.e., a NASA spokesperson), while for Democrats, the evidence was most effective when coupled with former US president Obama. Thus, even when accuracy primes work, their effects likely interact with other directional motivations making catch-all solutions difficult to enact [37**]. Other work shows that combining accuracy goals with normative goals, for example by communicating scientific consensus, can be effective in closing partisan gaps [40].

Activating non-partisan social identities may also be effective [41]. For instance, millennials are more likely to believe in anthropogenic climate change compared to older individuals who share their partisan identity [42]. Therefore, increasing the salience of their nonpartisan, generational identity may decrease the likelihood of relying on partisan identity when evaluating climate-related information. Educating children about climate change also influences their parents' climate change beliefs [43]. One recent study primed parental identity [44], compared to a partisan identity prime, priming a parental identity increased American Republicans' pro-environmental attitudes and intentions towards pro-climate behaviors (but had the opposite effect on Democrats). Notably, for both parties, the identity priming had little additional effect when compared to a third condition containing just pro-environmental information. Thus, it may be difficult to target the "right" identity to achieve desired effects, while activating the "wrong" identity can backfire (see [45*] for a meta-analysis). Partisans are not unitary and vary in the strength of their collective-identification, hence it can be difficult to design interventions based on identity targeting. As such, another option is minimizing the 
salience of political identities. For instance, one study found that removing identity cues reduced polarization in learning about climate change (compared to a condition where partisan identities were salient [46]. As such, if there is not a clearly effective strategy for priming alternative identities it may simply be easier to simply minimize the salience of partisan identities.

\section{Leveraging Identity}

Although it is very difficult to change someone's partisanship, it is possible to change the framing of pro-climate messages to harness these identities. For instance, framing a policy as being endorsed by one's political in-group leads to increased endorsement [47*], especially if it is also opposed by the out-group (e.g. [17*]). Identity-targeting message tailoring can also extend beyond partisanship. For example, Christians increased their pro-climate beliefs when presented with "stewardship" environmental messages compared to no messages [48]). This framing aligned with their Christian values in which humans are God' creations with a responsibility for caring for the Earth and its creatures.

Framing issues that do not trigger identity protective cognitions is another approach to leverage identity. By leaving "climate change" out of the equation entirely, or tapping into nonpartisan values, it is possible to bypass the role of belief in climate change in instigating proclimate protective behaviors. For example, conservative farmers in Alberta, Canada who adopt pro-environmental agricultural practices, construe these in an economical or efficient way. Similarly, support for carbon taxes increases among Swedish conservatives when coupled with a compensatory income-tax decrease [49], and such policy measures are perceived as being more fair.

This further suggests that moral values, such as fairness, may explain variance in climate change beliefs and pro-environmental behavior over that of partisan identification [50]. Similarly, framing a message in terms of conservative-values (i.e. emphasizing obedience, purity, and patriotism), increased conservation intentions and pro-environmental behavior amongst conservatives [47]. The message was more effective not only because of identity-value congruence, but also because it increased the perception of the source of the message being an in-group member [51] sum, framing messages about environmental protection as aligning with those values can increase that group's belief in climate change and participation in environmental protective actions.

\section{Future Directions}

A growing body of work highlights the relationship between partisan identity and climate change beliefs. However, there is a notable gap regarding the underlying psychological and neural processes in this domain. Future work needs to bridge the basic research we have reviewed and evaluate the causal relationships underlying actual pro-climate and sustainable belief and behavior. For instance, although there is a strong relationship between partisanship and climate change beliefs [3], it may be largely due to differences in prior beliefs, rather than motivated cognition [4], or even due to socio-economic or personality predictors [52]. Evaluating the link between political identity, motivation, and reasoning is complicated and some experimental designs undermine causal inference [53]. A social neuroscience approach may help adjudicate between competing theories and clarify our understanding of the underlying neural and psychological circuitry. 
A pressing need is to determine causal relationships and design effective interventions to help ground beliefs in more accurate information about climate change. One approach is intervention tournaments, which pit multiple interventions against each other in large samples (e.g., [54]). By comparing the effect size of different interventions on environmental beliefs and behavior, scholars can develop more precise theories and identify the strongest candidates for wide scale implementation.

Leveraging insights from social identity represents a promising avenue for future research. Indeed, a recent meta-analysis found a very strong link between pro-environmental social identities and pro-environmental collective actions [45]. While we believe successful interventions will involve targeting partisan identities, interventions also need to be carefully tailored to address the specific values and norms of relevant groups [3,6], as well as address complementary solutions coming from frameworks based on research on bounded rationality or social norms [55].

A final consideration is the relationship between beliefs and behavior. We need more explicit formal models that examine how beliefs about climate change translate into action. In many cases, the most effective interventions might completely bypass beliefs and operate directly on behavior (e.g., social norms), especially as research has found that climate beliefs do not always correlate with climate action [56]. In this way, norms, choice architecture, elite cues, and subtle nudges might be modified to alter behavior. Of course, we believe this approach will benefit immensely from an understanding of social identity to tailor messages appropriately.

\section{Conclusion}

The current paper reviews the role of partisan identity in climate change belief and behavior, and highlights the need for future research about various psychological and neural processes. Although we have reviewed several potential future interventions that show promise, without a better understanding of the underlying causal pathways that link identity with belief and behavior, it is likely that there may be several potent interventions that we have missed. Such work should be a priority for funding agencies, as well as more applied work in collaboration with organizations and policy makers. As climate change worsens, the need to understand these psychological and neural processes becomes more urgent.

\section{References}

[1] Masson-Delmotte V, Zhai P, Pörtner H-O, Roberts D, Skea J, Shukla PR, Pirani A, Moufouma-Okia W, Péan C, Pidcock R, et al.: Global warming of $1.5^{\circ} \mathrm{C}$ An IPCC Special Report. Rep Intergov Panel Clim Change 2018.

[2] Hornsey MJ, Fielding KS: Understanding (and Reducing) Inaction on Climate Change. Soc Issues Policy Rev 2020, 14:3-35.

**An action oriented review which describes research on how to understand and reduce public inaction in relation to climate change. Further, the authors propose various strategies that can be utilized in order to overcome many barriers to climate action, and promote pro-environmental behaviors.

[3] Smith EK, Mayer A: Anomalous Anglophones? Contours of free market ideology, political polarization, and climate change attitudes in English-speaking countries, Western European and post-Communist states. Clim Change 2019, 152:17-34.

[4] Bago B, Rand D, Pennycook G: Reasoning about climate change. PsyArXiv 2020, doi:https://doi.org/10.31234/osf.io/vcpkb.

[5] Steg L: Limiting climate change requires research on climate action. Nat Clim Change 2018, 
8:759-761.

[6] Czarnek G, Kossowska M, Szwed P: Right-wing ideology reduces the effects of education on climate change beliefs in more developed countries. Nat Clim Change 2021, 11:9-13.

[7] An Even More Partisan Agenda for 2008. Pew Res Cent - US Polit Policy 2008.

[8] Popovich N: Climate Change Rises as a Public Priority. But It's More Partisan Than Ever. $N Y$ Times 2020.

[9] Hornsey MJ, Harris EA, Fielding KS: Relationships among conspiratorial beliefs, conservatism and climate scepticism across nations. Nat Clim Change 2018, 8:614-620.

[10] Van Bavel J, Pereira A: The Partisan Brain: An Identity-Based Model of Political Belief. Trends Cogn Sci 2018, 22: 213-224.

*An opinion paper which suggests a model on how political identity biases information processing across a variety of cognitive functions (e.g. memory, perception, etc.).

[11] Kahan DM: Ideology, motivated reasoning, and cognitive reflection. Judgm Decis Mak 2013, 8:407-424.

[12] Cohen GL: Party Over Policy: The Dominating Impact of Group Influence on Political Beliefs. J Pers Soc Psychol 2003, 85:808-822.

[13] Rinscheid A, Pianta S, Weber EU: What shapes public support for climate change mitigation policies? The role of descriptive social norms and elite cues. Behav Public Policy undefined/ed, doi:10.1017/bpp.2020.43.

[14] Tesler M: Elite Domination of Public Doubts About Climate Change (Not Evolution). Polit Commun 2018, 35:306-326.

[15]Unsworth KL, Fielding KS: It's political: How the salience of one's political identity changes climate change beliefs and policy support. Glob Environ Change 2014, 27:131-137.

[16]Tarrant M, Haslam C, Carter M, Calitri R, Haslam SA: Social Identity Interventions. In The Handbook of Behavior Change. Edited by Hamilton K, Cameron LD, Hagger MS, Hankonen N, Lintunen T. Cambridge University Press; 2020:649-660.

[17]Van Boven L, Ehret PJ, Sherman DK: Psychological Barriers to Bipartisan Public Support for Climate Policy. Perspect Psychol Sci 2018, 13:492-507.

*An empirical paper which outlines the role of political polarization, and party norms, in climate policy adoption in the United States.

[18] The Politics of Climate Change in the United States. Pew Res Cent Sci Soc 2016, https://www.pewresearch.org/science/2016/10/04/the-politics-of-climate/

[19] Kammermann L, Dermont C: How beliefs of the political elite and citizens on climate change influence support for Swiss energy transition policy. Energy Res Soc Sci 2018, 43:48-60.

[20] Haslam SA, Reicher, SD, Platow MJ. The New Psychology of Leadership: Identity, Influence and Power. Routledge CRC Press. 2020

[21] Pärnamets P, Reinero D, Pereira A, Van Bavel J: Identity leadership: Managing perceptions of conflict for collective action. Behav Brain Sci 2019, 42: E136.

[22] Byrne S, Hart PS: The Boomerang Effect A Synthesis of Findings and a Preliminary Theoretical Framework. Ann Int Commun Assoc 2009, 33:3-37.

[23] Sparkman G, Walton GM: Dynamic Norms Promote Sustainable Behavior, Even if It Is Counternormative. Psychol Sci 2017, 28:1663-1674.

[24] Sparkman G, Walton GM: Witnessing change: Dynamic norms help resolve diverse barriers to personal change. J Exp Soc Psychol 2019, 82:238-252.

[25] Janssen M, Holahan R, Lee A, Ostrom E: Lab experiments for the study of social-ecological systems. Science 2010, 328:613-617.

[26] Brewer MB, Kramer RM: Choice behavior in social dilemmas: Effects of social identity, group size, and decision framing. J Pers Soc Psychol 1986, 50:543-549. 
[27] Van Vugt M, De Cremer D: Leadership in social dilemmas: The effects of group identification on collective actions to provide public goods. J Pers Soc Psychol 1999, 76:587-599.

[28] Molenberghs P, Louis WR: Insights From fMRI Studies Into Ingroup Bias. Front Psychol 2018, 9: 1868.

[29] Hughes BL, Zaki J, Ambady N: Motivation alters impression formation and related neural systems. Soc Cogn Affect Neurosci 2017, 12:49-60.

[30] Hackel LM, Zaki J, Van Bavel JJ: Social identity shapes social valuation: evidence from prosocial behavior and vicarious reward. Soc Cogn Affect Neurosci 2017, 12:1219-1228.

[31] Hackel LM, Wills JA, Van Bavel JJ: Shifting prosocial intuitions: neurocognitive evidence for a value-based account of group-based cooperation. Soc Cogn Affect Neurosci 2020, 15:371-381.

[32] Wells, CR, Huppert, A, Fitzpatrick, MC, Pandey, A, Velan, B, Singer, BH, ... \& Galvani, AP: Prosocial polio vaccination in Israel. Proceedings of the National Academy of Sciences 2020, 117(23), 13138-13144

[33] Turner JC, Oakes PJ, Haslam SA, McGarty C: Self and Collective: Cognition and Social Context. Pers Soc Psychol Bull 1994, 20:454-463.

[34] Fritsche I, Barth M, Jugert P, Masson T, Reese G: A social identity model of pro-environmental action (SIMPEA). Psychol Rev 2018, 125:245-269.

[35] Tam K-P: Understanding the psychology $\mathbf{X}$ politics interaction behind environmental activism: The roles of governmental trust, density of environmental NGOs, and democracy. $J$ Environ Psychol 2020, 71:101330.

[36] McFarland S, Hackett J, Hamer K, Katzarska-Miller I, Malsch A, Reese G, Reysen S: Global Human Identification and Citizenship: A Review of Psychological Studies. Polit Psychol 2019, 40:141-171.

[37] Druckman JN, McGrath MC: The evidence for motivated reasoning in climate change preference formation. Nat Clim Change 2019, 9:111-119.

**A review about the role of motivated reasoning in climate change acceptance. While many scholars argue that the motivated reasoning underlies the political divide's impact on climate change, this article carefully reviews a large portion of the empirical literature, and suggests that people are likely (also) driven by accuracy beliefs, but vary in what they consider to be credible evidence.

[38] Bolsen T, Druckman JN: Counteracting the Politicization of Science. J Commun 2015, 65:745769.

[39] Akin H, Hardy BW, Jamieson KH: Countering Identity-protective Responses to Climate Change Data. Environ Commun 2020, 14:1111-1126.

[40] Van der Linden S, Leiserowitz A, Maibach E: Scientific agreement can neutralize politicization of facts. Nat Hum Behav 2018, 2:2-3.

[41] Klandermans B: How Group Identification Helps to Overcome the Dilemma of Collective Action. Am Behav Sci 2002, 45:887-900.

[42] Ross AD, Rouse SM, Mobley W: Polarization of Climate Change Beliefs: The Role of the Millennial Generation Identity. Soc Sci $Q$ 2019, 100:2625-2640.

[43] Lawson DF, Stevenson KT, Peterson MN, Carrier SJ, L. Strnad R, Seekamp E: Children can foster climate change concern among their parents. Nat Clim Change 2019, 9:458-462.

[44] Diamond EP: The Influence of Identity Salience on Framing Effectiveness: An Experiment. Polit Psychol 2020, 41:1133-1150.

[45] Schulte M, Bamberg S, Rees J, Rollin P: Social identity as a key concept for connecting transformative societal change with individual environmental activism. J Environ Psychol 2020, 72:101525.

*This paper presents the results from three meta-analyses which establishes social identity as a relevant psychological concept to promote climate activism. 
[46] Guilbeault D, Becker J, Centola D: Social learning and partisan bias in the interpretation of climate trends. Proc Natl Acad Sci 2018, 115:9714-9719.

[47] Fielding KS, Hornsey MJ, Thai HA, Toh LL: Using ingroup messengers and ingroup values to promote climate change policy. Clim Change 2020, 158:181-199.

[48] Goldberg, M. H., Gustafson, A., Ballew, M. T., Rosenthal, S. A., \& Leiserowitz, A. (2019). A social identity approach to engaging Christians in the issue of climate change. Science Communication, 41(4): 442-463.

[49] Jagers SC, Martinsson J, Matti S: The impact of compensatory measures on public support for carbon taxation: an experimental study in Sweden. Clim Policy 2019, 19:147-160.

[50] Larsson J, Matti S, Nässén J: Public support for aviation policy measures in Sweden. Clim Policy 2020, 20:1305-1321.

[51] Feinberg M, Willer R: Moral reframing: A technique for effective and persuasive communication across political divides. Soc Personal Psychol Compass 2019, 13:e12501.

[52] Jylhä KM, Strimling P, Rydgren J: Climate Change Denial among Radical Right-Wing Supporters. Sustainability 2020, 12:10226.

[53. Tappin BM, Pennycook G, Rand DG: Thinking clearly about causal inferences of politically motivated reasoning: why paradigmatic study designs often undermine causal inference. Curr Opin Behav Sci 2020, 34:81-87.

[54] Lai, Calvin K., Allison L. Skinner, Erin Cooley, Sohad Murrar, Markus Brauer, Thierry Devos, Jimmy Calanchini, et al. "Reducing Implicit Racial Preferences: II. Intervention Effectiveness across Time." Journal of Experimental Psychology: General 2016. 145, no. 8: 1001-16.

[55] van der Linden S, Maibach E, Cook J, Leiserowitz A, Ranney M, Lewandowsky S, Árvai J, Weber EU: Culture versus cognition is a false dilemma. Nat Clim Change 2017, 7:457-457.

[56] Javeline D, Kijewski-Correa T, Chesler A: Does it matter if you "believe" in climate change? Not for coastal home vulnerability. Clim Change 2019, 155:511-532. 